\title{
A Content Analysis of Virtual Reality Studies in Foreign Language Education
}

\author{
Ekrem SOLAK* and Gamze ERDEM \\ English Language Teaching Department, Amasya University, Amasya
}

\begin{abstract}
The use of Virtual Reality in education has been highly prevalent in recent years. In nearly every domain of education, integration of Virtual Reality has been ongoing including foreign language teaching and learning. There is a huge shift in teaching and learning facilities from conventional classrooms to interactive ones. What makes Virtual Reality special in comparison to other technologies are immersion, interaction and involvement properties. Therefore, the purpose of this study was to analyze the studies on foreign language learning and teaching through virtual reality technology and to highlight the current trends on this topic, thus propose some suggestions for future researchers of this field. Document analysis method was used in this study. Like other analytical methods in a qualitative research, document analysis requires that data be examined and interpreted in order to elicit meaning, gain understanding, and develop empirical knowledge. 40 research papers published between the years 1995 and 2015 were scanned in terms of data collection tools, research design, sample, sample size, data analysis method, and the topic of the paper. The results of the study revealed that document analysis was in the first place in terms of data collection tool and half of the studies were qualitative. In addition, undergraduate population was primarily the focus of attention. As from sample size, 101-300 size was primarily used. Moreover, effectiveness of virtual reality and game-based learning were the two outstanding topics of these studies.
\end{abstract}

Keywords: language learning and teaching, virtual reality, VR in language education, technology

\section{Introduction}

In a world with digital natives, it seems inevitable not to realize technology integration into almost every domain of people's lives and daily activities. Technology has been integrated into people's lives via computers, mobile devices, social media platforms, digital cameras, etc. However in the last decades, the use of virtual reality for educational practices has increased. Many varied tools and practices of technology are available and educational practices can benefit from them with the effective use of technology in the teaching curriculum. As one of these offspring of technology, Virtual Reality (VR) can be defined as computer generated artificial worlds or immersive environments in which learners explore and interact with. The basic idea of VR is to give the impression and feeling of being

\footnotetext{
*English Language Teaching Department, Amasya University, Amasya, Turkey. ekremsolak@gmail.com
} 
somewhere else by tricking our brains in an artificial sensory world. Psotka (1995) states that "What distinguishes VR from all preceding technology is the sense of immediacy and control created by immersion: the feeling of "being there" or presence that comes from a changing visual display dependent on head and eye movements".

Various kinds of VR are available depending on the level of immersion and features. Main VR environments can be divided into 3 categories called text-based, graphical and three dimensional. Educational or social environment of text-based VR environments are MUD (Multi User Dungeon) and MOO (Multi-user domain, Object-Oriented). Compared to other VR environments, they enable low-cost, supportive environments for online activities. Graphical virtual reality environments are similar to text based ones. Differently, they integrate graphics to indicate users' domain in the environment and text is limited to speech bubbles. The last one is three dimensional (3-D) immersive virtual reality environments. They are high-tech, three dimensional sensory realities generally calling for head mounted displays and data gloves. Avatars, visual representations of users, symbolize their presence in the virtual reality environment. Most common 3D virtual reality applications are active world, second life, Croquet, etc.

In the light of recent studies, it seems quite reasonable to use virtual reality in learning and teaching foreign languages. When the learning is stimulating, children keep their attentions on language learning; therefore, in theory, the activities should be devised in a way that it will be attractive for learners (McGlothlin, 1997). Virtual reality gives the learners a feeling of presence in the learning environment and keeps them alert. Using virtual reality in language teaching can foster learning in that learners can behave differently in an online platform. People's behavior can change or at least appear to be different when working online compared to the behavior they would display in a classroom setting (Roed, 2003). Teachers can benefit from this situation by integrating virtual reality into traditional classrooms. Virtual reality is an ideal language learning environment that includes social learning, immersive learning, creativity and relevance. In 3D virtual environment, learners meet with others; they share and use their creativity by means of telepresence.

In this meta-analysis study, 40 articles about virtual reality and second language learning practices are analyzed with respect to specific domains. It is aimed that the results of this study will suggest a course of action for the future researchers about virtual reality and second language learning.

\section{Method}

Document analysis method was used in this study. Forty papers published in foreign language education through virtual reality in blind peer-reviewed journals were scanned in terms of data collection tools, research design, sample, sample size, data analysis method, and the topic of the paper. In this study, it was aimed to highlight the current trends in this field and to give some clues for future studies. The following hypothesis questions were answered in this study.

1. Which topics were frequently studied in these research papers?

2. What data collection tools were frequently used?

3. Which research designs were frequently applied?

4. What were the types and level of samples, and sample sizes in these research papers? 


\section{FINDINGS}

In this section, the data collected from the documents were assessed through excel program and presented in the form of tables below.

Table 1: Data collection tools

\begin{tabular}{lcc}
\hline Data collection tools & N & \% \\
\hline Observation & 1 & 2,5 \\
\hline interview & - & - \\
\hline achievement tests & - & - \\
\hline Questionnaire & 7 & 17,5 \\
\hline Documents analysis & 18 & 45 \\
\hline Alternative instruments & - & - \\
\hline More than once & 14 & 35 \\
\hline Total & 40 & 100 \\
\hline
\end{tabular}

Table 1 displays the number and the percentage of data collection tools used in the relevant literature. In these studies, Document analysis (45\%) was in the first place, and questionnaires $(17,5 \%)$ were in the second. In addition, in one study $(2,5 \%)$, observation was the data collection tool.

Table 2 : The research design of studies

\begin{tabular}{lcc}
\hline Research Design & N & \% \\
\hline Quantitative & 14 & 35 \\
\hline Qualitative & 20 & 50 \\
\hline Mixed & 6 & 15 \\
\hline
\end{tabular}

Table 2 shows the research design of studies conducted on this topic. While $50 \%$ were qualitative, $35 \%$ of the studies were quantitative. In addition, mixed design was used in $15 \%$ of the studies.

Table 3: The sample group and the sample size

\begin{tabular}{lcc}
\hline Sample & $\mathbf{N}$ & $\mathbf{\%}$ \\
\hline Elementary (1-4) & 1 & 2,5 \\
\hline Secondary (5-8) & 2 & 5 \\
\hline High school (9-12) & 2 & 5 \\
\hline Undergraduate & 11 & 27,5 \\
\hline Post graduate & 6 & 15 \\
\hline Not applicable & 17 & 42,5 \\
\hline Sample Size & $\mathbf{N}$ & $\mathbf{\%}$ \\
\hline $1-10$ & 2 & 5 \\
\hline $11-30$ & 5 & 12,5 \\
\hline $31-100$ & 6 & 15 \\
\hline $101-300$ & 7 & 17,5 \\
\hline $301-1000$ & 2 & 5 \\
\hline more than 1000 & - & - \\
\hline not applicable & 18 & 45 \\
\hline & &
\end{tabular}

Table 3 indicates the sample group and the sample size of the studies. While undergraduate population $(27,5 \%)$ was in the first place, postgraduates $(15 \%)$ were in the second. As from sample size, $101-300$ sample size $(17,5 \%)$ was primarily used and then $11-30$ size $(12,5 \%)$ was used in the second place. 
Table 4: Topic of papers

\begin{tabular}{lc}
\hline Topic of the paper & \\
\hline CALL & 3 \\
& $7,5 \%$ \\
\hline game-based learning & 7 \\
& $17,5 \%$ \\
\hline theoretical background and & 6 \\
literature review & $15 \%$ \\
\hline potential benefits and drawbacks & 5 \\
& $12,5 \%$ \\
\hline effectiveness of virtual reality & 14 \\
& $35 \%$ \\
\hline social networking & 1 \\
& $2,5 \%$ \\
\hline attitudes & 4 \\
& $10 \%$ \\
\hline Total & 40 \\
& $100 \%$ \\
\hline
\end{tabular}

Table 4 illustrates the topics of the papers published in this field. The effectiveness of virtual reality $(35 \%)$ was primarily the focus of attention. Secondly, game-based learning $(17,5 \%)$ was taken into consideration by the researchers. On the other hand, social networking was the aspect of virtual reality studied the least of all in foreign language education

\section{Discussion and Conclusion}

This study focused on the studies conducted in the domain of virtual reality and foreign language learning. Studies mentioned above are mostly qualitative in nature and as a data collection tool document analyses is the most commonly used one. Göktaş et al. (2012) and Kelly \& Lesh (2000) state that qualitative research methodology has started to be more preferred than quantitative methodology in recent years, and this study also supports their findings. Fifty percent of the studies analyzed above are qualitative. Moreover, in a literature review about recent developments in technology and language learning, Zhao (2003) asserts that experimental studies are inadequate about technological applications in language learning and most of the studies are descriptive or theoretical. With regards to sample, it is observed that undergraduate population is most prevalent and elementary sample population is the least common used. In the review of previous empirical studies conducted by Hew \& Cheung in 2010 about the use of 3-D virtual Worlds in both K-12 and higher education settings, it is also stated that most of the studies are conducted in university settings and they are mostly descriptive studies. Elementary, secondary and high school sample populations are lower compared to other populations. In the study of Zhao (2003), it is also stated that participants of all the analyzed studies are college students and adult learners. This situation threatens external validity of the conclusions. Learners may diverge in motivation, language background and learning styles. A document analysis study conducted by Korkmaz (2015) about new trends on mobile learning also supports the findings. It is asserted that most of the studies focus more on higher education and the number is relatively fewer in high school level. The probable reason behind this result can be explained in terms of interest group and study feasibility. Students in higher education can more effectively and commonly use technology for academic and social reasons and as researchers are in the university environment, it is easier for them to choose and observe the sample group for their studies. 
When the topic of the papers is examined it has been seen that studies center on the effectiveness of virtual reality and game- based learning follows this. In a study conducted by Hew \& Cheung in 2010, it is stated that earlier studies about virtual reality are mostly about media arts and health and environmental fields. This shows that virtual reality has started to be used more frequently in disciplines of education in the last decades. It is also seen that there is a gap in the literature about language teaching and learning by means of virtual reality in the area of CALL and social networking. Levy (1997) has stressed that one of the major obstacles to CALL research has been inadequate subsequent research in a new area and Second Life. As a new area of study in CALL, virtual reality assisted language learning (VRALL) should be emphasized. Consequently, it is seen that more studies should be conducted in the area of virtual reality and foreign language teaching and learning. Current studies conducted in this area show that when used properly, Virtual Reality can enhance foreign language learning to a great extent. However this meta-analysis shows us that the capacities of Virtual Reality have not been utilized adequately in foreign language teaching and learning facilities. Cuban (2001) asserts that the use of technology in classrooms is not adequate. It is also evident from the results that there is still more to be discussed in that area: implementation to the curriculum, evaluation process, social networking and virtual reality in CALL etc. As a suggestion for further studies, more longitudinal studies can be implemented to observe the effect of virtual reality reliably.

\section{References}

Aydin, S. (2013). Second Life as a Foreign Language Learning Environment: A Review of Research. Turkish Online Journal of Distance Education, 14(1), 53-63.

Corbin, J. \& Strauss, A. (2008).Basics of qualitative research: Techniques and procedures for developing grounded theory (3rd ed.). Thousand Oaks, CA: Sage.

Cuban, L. (2001). Oversold and underused: Computers in schools 1980-2000. Cambridge, MA: Harvard University Press.

Godwin-Jones, B. (2004). Emerging technologies: Language in action: From webquests to virtual realities. Language Learning \& Technology, 8(3), 9-14.

Goktas, Y., Kucuk, S., Aydemir, M., Telli, E., Arpacik, O., Yildirim, G., \&Reisoglu, I. (2012). Educational technology research trends in Turkey: A content analysis of the 2000-2009 decade. Educational Sciences: Theory \& Practice, 12(1), 177-199

Hew, K. F., \& Cheung, W. S. (2010). Use of three-dimensional (3-D) immersive virtual worlds in K-12 and higher education settings: A review of the research. British journal of educational technology, 41(1), 33-55.

Hışmanoğlu, M. (2012).Integrating Second Life into an EFL classroom: A new dimension in foreign language learning and teaching. International Journal on New Trends in Education and Their Implications, 3 (4), 100, 111.

Ioannou-Georgiou, S. (2002). Constructing meaning with virtual reality. TESOL Journal, 11(3), 21-26.

Kelly, A. E., \& Lesh, R. A. (2000). Trends and shifts in research methods. In A. E. Kelly, \& R. A. Lesh (Eds.), Handbook of Research Design in Mathematics and Science Education (pp.35-44). Mahwah, NJ: Lawrence Erlbaum Associates.

Korkmaz, O. (2015). New Trends on Mobile Learning in The Light of Recent Studies. Participatory Educational Research (PER) Vol. 2(1), pp. 1-10.

Levy, M. (1997). Computer-assisted language learning: Context and conceptualization. Oxford: Clarendon Press. 
McGlothlin, J. D. (1997). A child's first steps in language learning. The Internet TESL Journal, 3. (10).

Moore, P. (1995). Learning and teaching in virtual worlds: Implications of virtual reality for education. Australasian Journal of Educational Technology, 11(2).

Psotka, J. (1995). Immersive training systems: Virtual reality and education and training. Instructional science, 23(5-6), 405-431.

Rapley, T. (2007). Doing conversation, discourse and document analysis. London: Sage.

Roed, J. (2003). Language learner behaviour in a virtual environment. Computer assisted language learning, 16(2-3), 155-172.

Zhao, Y. (2013). Recent developments in technology and language learning: A literature review and meta-analysis. CALICO journal, 21(1), 7-27. 